\title{
Prácticas cotidianas de ancestralización de un territorio indígena: el caso de la comunidad pewenche de Quinquén ${ }^{1}$
}

\author{
Nelson Martínez Berríos²
}

\begin{abstract}
RESUMEN
Este artículo explora la dimensión ancestral de la vida en la comunidad pewenche de Quinquén en el sur de Chile. Mediante el examen de distintas prácticas sociales, se identifica una pluralidad de formas a través de las cuales los habitantes de la comunidad ancestralizan su territorio. Este proceso de ancestralización subyace a varios aspectos de la vida en Quinquén, haciéndose sobresaliente e incluso visible, tanto hacia el interior como hacia el exterior de la comunidad. Se postula que la ancestralización del territorio es un proceso continuo que se encuentra enlazado a la forma de vida de las familias que conforman la comunidad, mediante nexos que mantienen la continuidad espacio-temporal de las relaciones sociales. Se busca con ello aportar al reconocimiento de una geografía indígena enlazada a la vida cotidiana. Una mayor consideración a estos aspectos, podría contribuir a una necesaria reflexión sobre lo que es vivir en una comunidad indígena. Pero más importante aún, podría contribuir a entender lo que significa hoy en día ser pewenche. El artículo está organizado en tres secciones: la primera analiza el campo de relaciones de poder, la segunda la estructura social, y la tercera las estrategias de control del territorio.
\end{abstract}

Palabras clave: Ancestralización, control del territorio, geografía indígena, territorialidad pewenche.

\begin{abstract}
This article explores the ancestral dimension of the life in the pewenche community of Quinquen, in Southern Chile. It examines different social practices, in order to identify the plurality of form used by the community's inhabitants to ancestralize their territory. This process of ancestralization underlies various aspects of life in Quinquén and has become notable or even visible, both to the community and to outsiders. It is postulated that ancestralization of territory is a continuous process that is linked to the lifestyles of the families that compose the community, through links that keep the continuity of social relationships across time and space. The purpose of this is to contribute to the recognition of an indigenous geography embedded in the everyday life. Greater consideration of these aspects could contribute to a critical reflection on what it means to live in an indigenous community. But more importantly, it could contribute to understanding what it means to be pewenche today. The article is organized into three sections: the first analyzes the field of power relations, the second social structure, and the third strategies of territorial control.
\end{abstract}

Key words: Ancestralization, space control, indigenous geography, pewenche people territoriality.

1 El autor agradece especialmente las agudas observaciones de Bastien Sepúlveda y de los revisores anónimos, cuyos comentarios permitieron mejorar notablemente este trabajo. Los errores y omisiones cometidos son de mi entera responsabilidad. Este trabajo forma parte de la investigación doctoral en la Universidad de California, Davis, financiada por Becas-Chile. Artículo recibido el 30 de abril de 2015, aceptado el 3 de agosto de 2015 y corregido el 11 de septiembre de 2015 .

2 Escuela de Ciencias Ambientales, Universidad Católica de Temuco (Chile). E-mail: nmartinez@uct.cl 
El interés por el estudio de los territorios ancestrales indígenas, desde el campo de la geografía, coincide con el denominado "giro cultural" de la disciplina (Philo 2000). Este interés, aunque convergente, muestra trayectorias diversas. Por ejemplo, desde un enfoque de la ecología cultural, Nietschmann (1989, 1990, 1995) estudia los derechos tradicionales a los recursos terrestres y marinos de los miskitos en Nicaragua, abriendo una línea de investigación que tuvo gran impacto entre algunos geógrafos norteamericanos, quienes a partir de entonces comenzaron a vincular sus trabajos académicos con las demandas territoriales de los grupos con los que colaboran. Así, esta vertiente fue seguida desde la geografía histórica por Offen (2003, 2008, 2009,); desde la cartografía crítica por Wainwright \& Bryan (2009), y Bryan \& Wood (2015); y desde la geografía poscolonial por Wainwright $(2011)^{3}$. Estos esfuerzos también han desempeñado un papel importante en conectar el campo del derecho indígena con la geografía, mediante la delimitación de la propiedad indígena apoyada en títulos coloniales y estatales.

En Chile, el interés de los geógrafos por las territorialidades indígenas, no es algo que pueda darse por supuesto, como lo revela la escasa literatura existente sobre el tema, producida desde la geografía. En esta línea, Sepúlveda (2012) sostiene que la geografía ha permanecido inexplicablemente ausente de los debates sobre cuestiones territoriales indígenas. No obstante, es posible destacar algunos trabajos importantes que han hecho contribuciones al emergente campo de las geografías indígenas.

Molina (1995) abre una nueva senda para la geografía, al proponer el concepto de et-

\footnotetext{
3 Muchos de los autores mencionados tomaron parte activa en el Caso de la Comunidad Mayagna (Sumo) Awas Tingni Vs. Nicaragua llevado a la Corte Interamericana de Derechos Humanos y que ha sido ampliamente documentado por la literatura. Este caso además sentó un precedente importante para la protección y defensa de los derechos indígenas. Pero sobre todo sentó un precedente para movilizar la noción de territorios ancestrales a las demandas y reivindicaciones por la restitución de tierras. Para un análisis más detallado del alcance de este caso ver el trabajo de Aylwin y Cuadra (2011).
}

noterritorios a partir de los cuales se podría reconstruir la territorialidad indígena. En la misma perspectiva de la reconstrucción territorial, pero en concordancia con el enfoque poscolonial, Hirt $(2006,2012)$ propone el uso de contracartografías para la reconstrucción territorial de las antiguas ocupaciones indígenas. Por su parte, usando un enfoque metodológico de la investigación acción, Palomino-Schalscha (2012), examina la experiencia de los emprendimientos turísticos pewenche de Trekaleyin como una estrategia innovadora de construcción relacional de lugares. Más recientemente, en un intento por desafiar visiones convencionales de conservación, Guyot \& Sepúlveda (2014) exploran las reconfiguraciones étnicas territoriales de atacameños y pewenches en zonas de fronteras internacionales, analizando los modelos de participación en programas de comanejo de áreas protegidas. Tomada en su conjunto, toda esta esta literatura permite apreciar, la relevancia que la territorialidad indígena ha adquirido para la geografía y en particular el renovado interés por indagar en el carácter ancestral de esa territorialidad. Este artículo contribuye a esta creciente literatura sobre las distintas formas en que se manifiestan las geografías indígenas.

Si bien existe cierto consenso en la literatura sobre derecho indígena respecto al concepto de territorios ancestrales, poco se sabe sobre la forma en que la dimensión de lo ancestral ${ }^{4}$ se expresa en los territorios. Este artículo intenta llenar ese vacío de conocimiento aportando evidencia sobre la dinámica de ancestralización del territorio de la comunidad pewenche de Quinquén. Se postula que la ancestralización del territorio, es un proceso continuo que se encuentra enlazado

\footnotetext{
4 El concepto de lo ancestral, no es del habla común de los pewenche, sin embargo, hoy en día es fácil escucharlo en el discurso de los jóvenes o leerlo en el material gráfico producido con fines turísticos. Se trata, por lo tanto, de un concepto introducido que ha adquirido un carácter estratégico. Con todo, existe una noción compartida acerca de la vinculación de las actuales familias con sus antepasados y que se expresa mediante prácticas como: el lakutun, darse el nombre entre generaciones alternadas; la existencia de dos eltun (cementerios) uno antiguo y uno moderno; y los relatos de pasadas guerras contra invasores españoles, argentinos y chilenos, por mencionar solo algunos ejemplos.
} 
Figura $\mathrm{N}^{\circ} 1$

Localización de la comunidad mapuche pewenche de Quinquén
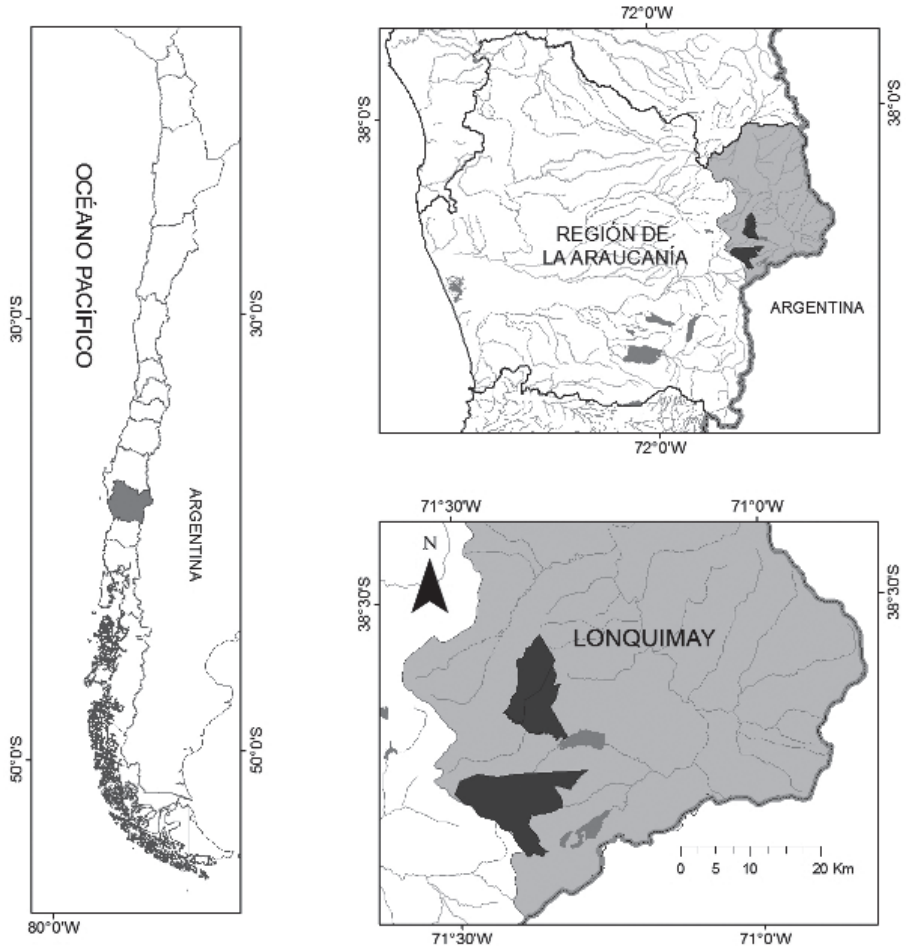

Fuente: Elaborado por Viviana Huiliñir-Curío.

a la forma de vida de las familias que conforman la comunidad, mediante nexos que mantienen la continuidad espacio-temporal de las relaciones sociales. Dichos nexos son articulados: a) por el poder simbólico que se manifiesta en las distintas formas de producción de autoridad, legitimidad y prestigio tanto interno como externo; b) por la estructura social que se expresa en las relaciones de parentesco, las prácticas matrimoniales y la organización de la familia; y c) por el control territorial expresado en el establecimiento de límites, los usos del territorio, y las relaciones recíprocas que se establecen con los animales, los antepasados, los bosques, los espíritus tutelares, las montañas y el propio territorio. Se trata entonces de un proceso dinámico y específico que se da en la geografía cultural de un lof pewenche. Con el propósito de explicar esas dinámicas, el artículo se estructura en tres secciones: la primera analiza el campo de relaciones de poder, la segunda la estructura social, y la tercera las estrategias de control territorial.

Los datos contenidos en este texto fueron recogidos mediante entrevistas informales, observación directa, y participación en las actividades de la vida cotidiana de la comunidad, trianguladas luego con material de archivo y un amplio registro fotográfico. Estos datos fueron puestos en diálogo crítico con una extensa bibliografía, a fin de ampliar la comprensión de las prácticas sociales mapuche ancladas al territorio. La recolección de datos se realizó durante un periodo no continuo pero sistemático entre julio de 2010 y junio de 2011, complementada por varias visitas posteriores de corta duración. El estudio desde donde surge este artículo, se realizó con el consentimiento expreso e informado obtenido individual y colectivamente de las familias de la comunidad de Quinquén. 
La comunidad pewenche de Quinquén es una agrupación humana conformada por aproximadamente 250 personas distribuidas en 52 familias, que habitan un espacio físico bien delimitado, reconocido cultural y legalmente como un territorio indígena. Está emplazada en la zona cordillerana de Lonquimay en la Región de la Araucanía en las nacientes del río Biobío (Figura $N^{\circ} 1$ ). Sus miembros reconocen a los antepasados que dieron origen a su linaje cuya genealogía se remonta a cinco generaciones, su patronímico está emparentado con un animal tutelar. Comparten una memoria social de lucha que les otorga un relato a su pasada resistencia ante los intentos de desposesión, pero también a sus demandas contemporáneas 5 . Se organiza según protocolos de convivencia tradicional y moderna que coexisten en una pluralidad de instituciones de poder colegiadas y unipersonales. Conservan, además de su lengua, costumbres espirituales individuales, familiares y colectivas altamente ritualizadas cuya máxima expresión es el nguillatún. Sus medios de vida dependen casi en su totalidad de los recursos que les proporciona el ambiente, razón por la cual despliegan una serie de estrategias de acceso, control y uso que les permiten disponer de esos recursos, entre los que se cuentan leña, pasto para los animales, y piñones, además de los dones o habilidades que la mayoría de los miembros posee y que constituyen su capital. Se relacionan con el mundo natural y sobrenatural a través de distintas acciones de la vida cotidiana e interactúan con las instituciones públicas y privadas vinculadas a la política indígena.

5 Una parte significativa de la lucha de los habitantes de este territorio por el reconocimiento de sus derechos ancestrales, es relatada en el libro de José Bengoa, Quinquén Cien Años de Historia Pehuenche, que cubre hasta el año 1992. Según este autor "Quinquén puso el tema indígena en la conciencia nacional" (Bengoa 1992:9). En efecto, en el marco de la denominada emergencia indígena en América Latina y en la coyuntura precisa de los 500 años de la invasión española al continente, este caso sacó a la luz los testimonios de estas familias, revelando así la persistencia de su modo de vida. Más recientemente Ximena Cuadra, analiza el proceso transformación de la comunidad en un Territorio Indígena de Conservación (Aylwin y Cuadra: 2011), este proceso aún no ha terminado de cuajar.

\section{Poder}

Aunque no existe consenso sobre la forma en que se construyen los nombres propios de las personas en la sociedad mapuche (Foerster, 2010), en los apellidos actuales se observan ciertas regularidades vinculadas al sistema de creencias, entre las que destaca una característica división en dos partes pertenecientes al universo simbólico. En el caso del patronímico Meliñir, cuya traducción en mapudungun es "cuatro zorros", las partes que lo componen son las voces meli -cuatro- y ngürü -zorro-, ambos elementos, como se verá, poseen un significado cultural para el pueblo mapuche. Efectivamente, tanto el numeral cuatro, como el animal zorro ocupan un lugar central en las experiencias cotidianas de vida, que se integran al mundo simbólico, en el ordenamiento espacial y "en el protocolo mapuche de relación con la naturaleza" (Neira et al., 2012: 314).

Por una parte, el numeral cuatro, es constitutivo de la esencia del ser y es reconocido como parte fundamental para la transmisión del conocimiento y la vida, pero también para la conservación del equilibrio, justamente cuatro son los orígenes del linaje de cada persona, esto es abuelo y abuela paterna y abuelo y abuela materna o meli tuwün wixanentukeyiñ (COTAM, 2003: 1277). Lenz (1897: 231), anota que el cuatro es un número sagrado, de ahí que "todas las invocaciones, etc. se hacen cuatro veces", este carácter sagrado se manifiesta también en la creencia en un ordenamiento espacial cuatripartito. Un ejemplo que ilustra bien este ordenamiento, se expresa en el concepto de meli witrán mapu que significa "tierra de los cuatro lugares" (Grebe, 1972) y cuya manifestación más gráfica son los diseños del kultrún o tambor ritual de la machi (Grebe, 1973).

El elemento animal, en tanto, está presente en los apellidos mapuche de distintas regiones, aunque el zorro es más común en los apellidos de los grupos que viven en las zonas cordilleranas. Con todo, el zorro, es un animal omnipresente en la geografía cultual pewenche ocupando un lugar destacado en el imaginario colectivo de este pueblo, es por ello que se le considera un "animal tutelar" cuya presencia se aprecia en muchos relatos mitológicos (Villagrán, 1999: 604) y narracio- 
nes orales o epew (Foerster, 1993). El zorro, sin embargo, presenta características que incluyen rasgos contradictorios, algunos positivos como la astucia y otros negativos como ser señal de malos augurios y el daño y robo a las aves de corral. Pese a ello los portadores actuales del apellido se identifican fuertemente de la relación existente con el animal.

Según algunos autores (Latcham, 1924; Foerster, 1993), el vínculo animal-linaje sería indicativo de la persistencia del culto totémico. El tótem era el símbolo que representaba la alianza entre algún espíritu protector encarnado en un ser del mundo natural y el fundador del linaje. Pese a que el origen totémico de los clanes mapuche es un asunto controversial y se mantiene aún sin resolver (Zavala 2008:76), la persistencia del linaje Meliñir así como la mantención de sus lazos de parentesco, permite identificar dos componentes clave en la reproducción de la ancestralidad, como son el sistema de filiación patrilineal y la residencia patrilocal.

El origen del linaje Meliñir ha podido rastrearse hasta 1906, fecha en que se otorgó el Título de Merced al cacique Paulino Huaiquillán, en el sector que hoy es conocido como Pedregoso (Bengoa, 1992). En dicho instrumento se consagra por primera vez la existencia formal, del que sería el antepasado más antiguo de los actuales integrantes de la comunidad de Quinquén, hecho que indicaría también, que el nombre ya figuraba entre los posibles miembros de alguna estructura social, que pudo ser un caserado, esto es una familia nuclear o bien una familia extendida. Con todo, al ser incorporados al título que dio origen a la Reducción o Reserva Indígena Paulino Huaiquillán, los Meliñir pasaron a ser uno más entre los linajes que se radicaron en la reducción y por lo tanto debían reconocer la autoridad del cacique, a cuyo nombre se concedió el Título de Merced (T.M.). La presencia de linaje Meliñir en el T.M. fue la base para el reclamo de ocupación ancestral sobre el territorio que ocupan actualmente.

La Reducción de Pedregoso fue el lugar de asentamiento original del linaje Meliñir o donde estaba su mapu tierra, allí establecieron su punto de referencia espacial, social y temporal, hasta radicarse posterior y definitivamente en Quinquén donde estará su nuevo mapu. La comprensión de esta práctica, que permite trasladar la pertenencia de los sujetos a otro lugar, es crítica para explicar el vínculo que los mapuche contemporáneos mantienen con la tierra, así como también la emergencia de proyectos políticos de reterritorialización. Este práctica de recrear el vínculo con el mapu se conoce como el Inche ñi mapu Tuwün, expresión que no tiene una traducción literal en español pero su significado es el equivalente a un tipo de relación totalizante que se crea con el territorio que se habita. Este concepto de Inche ñi mapu Tuwün es explicado aquí por uno de mis colaboradores pewenche en sus propias palabras:

Los mapuches en si el espacio territorial es uno de los más importantes ya que la tierra es vida, aunque no se trabaje para fines productivos solo se consideraba el vivir o el sobrevivir de ella, para nuestros abuelos y nuestros antepasados siempre valoraron es espacio territorial de un todo donde coexisten diferentes seres o Itrofil nguen y el Itrofil monguen que significan aquellos que no tienen vida y los que tienen vida todos son importantes ya que cumplen un rol enorme en la tierra, incluso lo que no se ve o sea los ngenes, las energías negativas y positivas que existen en cada elemento de la tierra, que hoy solo las personas con sabiduría mapuche pueden darle importancia a esto ya que mucho por la intervención de las religiones y por el sistema de educación que se imparte en Chile se han perdido costumbres, idioma, valores, y respeto.

El concepto de Inche ñi mapu Tuwün entonces, más que indicar el lugar de nacimiento de las personas, es la expresión que recoge el significado de una forma de ser en el espacio (Cfr. Marimán et al. 2006: 29). También es la expresión que demuestra la existencia de un protocolo de relaciones entre los humanos con la naturaleza y los seres que la habitan, pero fundamentalmente es la forma mediante la cual se expresa la territorialidad mapuche.

\section{Autoridad, legitimidad y prestigio interno}

En el plano de la organización interna, el tener hijos en especial hombres, ha sido y sigue siendo una importante fuente de prestigio y reproducción social. Antiguamente tenía 
una importancia en la medida que permitía a los jefes de familia disponer de mayor contingente de mano de obra y a la vez mantener los derechos territoriales, esta última característica sigue vigente aunque dado que la superficie comunitaria es limitada, el tener más hijos no permite una expansión territorial, aun cuando permite la postulación a tierras en otros sectores. En el orden de la micropolítica las familias numerosas y con mayor número de miembros con 'casa aparte', disponen de más fuerza en la configuración de las relaciones de poder, en tal sentido constituyen la base social que otorga legitimidad a la autoridad del longko.

El longko (cabeza) es la máxima autoridad político-religiosa de un lof o comunidad pewenche, tradicionalmente esta autoridad era elegida por los jefes de familia que componían una unidad mayor o patrilinaje, es decir, se accedía al cargo por mérito. Sin embargo, con el advenimiento del sistema de reducciones (1884-1929) surgen los derechos hereditarios con la consecuente aparición de "castas de poder" (Bengoa. 2000: 67), a partir de entonces la trasmisión del poder pasa a ser hereditaria de manera más formal y sistemática. Dado que la familia Meliñir era un linaje bajo la autoridad del cacique de Pedregoso no tenía un longko formalmente reconocido, una vez que se instalaron definitivamente en Quinquén (1956) y se vieron forzados a renunciar a sus derechos en su antiguo mapu, eligieron a don Armando Meliñir Ñanco, Kolumil6 (1917-2006) como el primer longko del linaje. Este jefe demostró poseer altas cualidades de liderazgo las que le permitieron guiar a la familia al reconocimiento de sus derechos ancestrales sobre el territorio que hoy ocupan.

En la actualidad el rol de longko es detentado por don Ricardo Meliñir Marihuan, quien lo heredó de su padre. Al respecto, es interesante señalar dos cosas; la primera es que el título no se hereda automáticamente al hijo mayor y la segunda es que el título no

\footnotetext{
6 El nombre Kolumil corresponde al nombre propio que recibían las personas antiguamente y que era independiente al nombre propio que figuraba en el certificado de nacimiento. Esta costumbre no se conserva en la actualidad.
}

es vitalicio, como lo demuestra el hecho de que el actual longko no era el primogénito de su padre, este último le delegó su autoridad principalmente por razones de salud. Así, mientras que don Armando como primer longko fue elegido por los jefes de familia, don Ricardo lo heredó de su padre. Entre las principales atribuciones de la institución del longko como máxima autoridad, destaca el reconocimiento de su investidura tanto por los integrantes, de la propia comunidad como de otras comunidades pewenche, en tal capacidad debe mantener la unidad de su grupo actuando como mediador cuando es requerido y además debe actuar como representante de la comunidad en eventos de carácter cívico, en el plano religioso es quien convoca y dirige el ritual del nguillatún, a diferencia de lo que ocurre en otros lugares donde es la machi quien cumple esta función.

Junto con el poder simbólico que representa detentar la calidad de longko también destaca el prestigio que es reconocido aún por personas no pewenche, aunque esto no ha sido siempre así como lo demuestran los esfuerzos de instituciones de la sociedad civil local por restituir el poder social de estas autoridades integrándolos al consejo comunal. Si bien la condición de longko es de carácter permanente, es decir es un atributo encarnado en el individuo que lo posee, no existen símbolos externos que lo diferencien del común de las personas ${ }^{7}$, sin embargo cuando actúa en su rol de autoridad tradicional, casi sin excepción usa su manta de cacique, en especial cuando debe interactuar con otros longkos.

En el mundo mapuche tradicional la machi era y sigue siendo una autoridad de carácter ritual de gran importancia, pero su rol es distinto al del longko (Dillehay, 1985). La machi cumple funciones de sanación y es por lo tanto un agente fundamental en la mantención y transmisión de la cultura (Bacigalupo,

\footnotetext{
7 Una de las principales características de la vida en comunidad es la horizontalidad de las relaciones sociales, por esta razón el longko actúa como uno más de los miembros del grupo sin hacer ostentación de ninguna clase de autoridad que lo diferencie del resto del grupo, su jerarquía por lo tanto es de orden simbólico.
} 
2001). Sin embargo, entre los pewenche no es frecuente encontrar machi como lo fue en el pasado, aunque su poder sanador sigue siendo demandado, para estos efectos deben buscarlas en otras comunidades, o acudir centros de salud intercultural ${ }^{8}$.

Recientemente la comunidad ha entrado en un proceso de formación de una machi, lo que le otorgaría más newen o fortaleza interna, así como también prestigio ante otras comunidades. La machi a diferencia del longko, se forma específicamente para desempeñar un rol espiritual y médico luego de que la persona, sea hombre o mujer, recibe un Ilamado que por lo general se expresa a través de sueños premonitorios, por esta razón quienes reciben este llamado sufren fuertes crisis de identidad que afectan también a toda la familia, puesto que el recibir este llamado implica una gran responsabilidad cultural, además de costos económicos asociados a la formación de la machi, tales como viajes periódicos, permanencia en otras comunidades y lo que significa ponerse bajo la tutela de otra machi, por estas razones la decisión de perseverar en el proceso formativo de una machi es algo que trasciende al individuo siendo de interés para su familia, para la comunidad y también para las comunidades adyacentes, específicamente por el poder que tiene la machi de invocar a los espíritus ancestrales (Bacigalupo, 2001).

Existen en la comunidad personas sin rango formal de autoridad que poseen un gran prestigio, dicho prestigio proviene de dos fuentes: la primera es la pertenencia a las cuatro familias fundadoras, se entiende por esto a quienes primero se establecieron en el lugar de forma más permanente, con-

\footnotetext{
8 La promoción de las terapias médicas de la machi, así como su integración formal al sistema de salud, es un asunto controversial, mientras que para el programa de Salud Intercultural creado al amparo del Programa Orígenes es una forma de recuperación de prácticas ancestrales o de sensibilización hacia la salud indígena, para otros es visto como una forma de intervención de los espacios sagrados mediante la etnogubernamentalidad. Para una discusión más en profundidad sobre este tema, ver el interesante trabajo de Boccara (2007). En cualquier caso se trata de un tema inserto en el ámbito de las disputas por el poder espiritual del cual la comunidad no es ajena.
}

viene recordar que originariamente el linaje Meliñir formaba parte de la Reducción de Paulino Huaiquillán y su asentamiento definitivo en Quinquén ocurrió en el transcurso de varias décadas (Bengoa, 1992). El esfuerzo de estas familias, que durante décadas fueron consideradas ocupantes ilegales, contribuyó a establecer las bases del derecho de ocupación ancestral del territorio, es por ello que hoy en día gozan del reconocimiento, no solo de la totalidad de los integrantes de la comunidad, sino también de organizaciones y personas externas a ella. La segunda fuente de prestigio proviene de haber participado activamente en el largo proceso que culminó con la obtención de los títulos de las tierras, este proceso permanece vivo en la narrativa oral de la comunidad, conformando lo que Gordon y Hale (2003) Ilaman una "memoria social de lucha". Esta memoria es recreada permanentemente mediante la retórica política que se expresa de múltiples formas, entre las cuales se cuenta: la presentación de la comunidad frente a los extraños, la producción audiovisual creada más recientemente, y los relatos descriptivos en documentos escritos.

La construcción y registro de esta memoria ha sido un proceso sistemático que se inicia con el despliegue mediático que se centró en "la lucha" de Quinquén a fines de 1980 y principio de 1990 y que puso en contacto a los líderes de la comunidad con activistas, ambientalistas, pero sobre todo con la dirigencia indígena nacional, que por ese entonces se encontraba en un proceso de efervescencia producto del retorno a la democracia. El siguiente testimonio entregado a la prensa por uno de los integrantes de la primera generación de líderes, recoge el espíritu guerrero y el sentido de trascendencia que tenía para ellos el reconocimiento de sus derechos ancestrales: "Nosotros somos representantes de la causa mapuche y el destino de los mapuche se está jugando en Quinquén. Todo lo que aquí suceda será reconocido por nuestros hermanos" 9 .

Ciertamente, las precarias condiciones materiales de los participantes en ese proceso reivindicativo, sumado a la posibilidad real

\footnotetext{
9 Diario La Tercera, 15 de febrero de 1992.
} 
de ser desalojados de las tierras hacían prácticamente imposible la obtención de un resultado satisfactorio para las familias que en ese entonces componían el grupo. Sin embargo, los líderes del movimiento con la ayuda de otros actores indígenas y no indígenas, lograron sortear con éxito una serie de obstáculos de orden cultural, jurídico y político lo que les otorgó una gran habilidad de negociación incluyendo, tratativas con autoridades, ministros y hasta el propio Presidente de la República las que finalmente lograron atraer a su causa una serie de intereses que posibilitaron el reconocimiento de sus derechos ancestrales sobre el territorio.

La posesión de ciertos dones o habilidades es reconocida también como una forma de prestigio, entre los dones que otorgan prestigio que pudieron ser observados en el campo destacan: los relacionados con la conservación de las tradiciones orales: ewpichefe, conocedor de la historia; epewtufe, narrador de la tradición oral una especie de cuenta cuentos; y kimche estos son los sabios o portadores de kimün o conocimiento ancestral. Los relacionados con el ritual del nguillatún: afkadi, ayudante del longko; kultruntufe, el que toca el kultrún; trutrukatufe, el que toca trutruka; tayelve, las mujeres que cantan; tawïneltu, que es el danzante más destacado. Los que poseen conocimientos médicos: lawentuchefe, que posee el don de reconocer y utilizar las plantas medicinales; püñeñelchefe, mujeres con conocimientos sobre el embarazo y parto; y pewmatufe, intérprete de sueños pneuma, poseer este don es muy importante toda vez que los sueños premonitorios son un componente importante del sistema de creencias. Los que poseen conocimientos técnicos: düwekafe que posee el don para confeccionar textiles en especial los que son hechos a telar o ñiminchefe; mamüll kamañ, artesano en madera, rukafe, que posee el don para la construcción de (rukas) casas. Dada la naturaleza eminentemente horizontal de la sociedad mapuche, estas formas de prestigio no confieren posiciones de orden jerárquico, pero sí contribuyen a la interdependencia comunitaria en torno a saberes ancestrales.

Otra fuente de prestigio muy arraigada en la cultura pewenche, es la riqueza material como la expresada en la posesión de ani- males de ganado mayor, el ganado vacuno es considerado además como un importante recurso económico, en especial las yuntas de bueyes (Aravena. 1995). En la actualidad la posesión de vehículos confiere cierto estatus pero no necesariamente prestigio.

\section{Autoridad, legitimidad y prestigio externo}

Las transformaciones estructurales en la forma de organización de las familias, debilitaron considerablemente la autoridad de los longkos en favor de la figura de un dirigente de carácter funcional encarnado en el presidente de la comunidad, pese a esta tensión, existe la posibilidad de que el longko ejerza el cargo de presidente, concentrando de esta forma en una sola persona la autoridad tradicional y moderna. El presidente es una institución de carácter unipersonal y electiva que emerge al amparo de la Ley Indígena $N^{\circ} 19.253$ de 1993, su poder emana de la asamblea de socios que se rige por estatutos propios con arreglo a la ley antes señalada, se trata entonces de una institución de origen democrático creada, por una parte, con el propósito de organizar la vida comunitaria, y por la otra, de servir como dispositivo de enlace entre la comunidad y el aparato burocrático del Estado. El poder real del presidente y de la directiva que lo acompaña es limitado, toda vez que sus decisiones deben contar con la venia de la asamblea. Asimismo, este poder es en gran medida el resultado combinando de una serie de factores como son: a) las características personales y liderazgo del presidente, b) la correlación de fuerzas entre las familias que se expresa en la composición de la directiva, y c) en la capacidad del presidente para movilizar intereses. Con todo, el presidente es el representante legal de la comunidad para efectos de orden administrativo y en tal calidad goza de reconocimiento y prestigio externo.

Si bien es cierto, esta institución es de carácter exógeno, en tanto establecida de manera forzosa por la ley e introduce una dualidad de poder entre dos tipos de autoridad, sería erróneo verla como algo exclusivamente disfuncional. Por otra parte, la constitución de la comunidad como una figura legal y seguidamente la emergencia del presidente, se produce el año 1995 es decir con posterioridad a la dictación de la ley de 1993, eso 
significa en la práctica que la comunidad virtualmente nace con la ley y desde entonces ha debido adaptase a esta realidad, la que ha traído consigo contradicciones internas, pero también ha traído beneficios. Finalmente, pese a que una parte importante del grupo manifestó su resistencia inicial a constituirse legalmente como comunidad, la situación actual evidencia una fuerte capacidad de adaptación al cambiante contexto de las políticas indígenas. En consecuencia, esta forma institucional de organización indígena, más que ser una amenaza encaminada hacia la desintegración social, bien puede contener las bases de la rearticulación para el ejercicio de la política, lo que se evidencia en los continuos arreglos y negociaciones internas para alcanzar equilibrios de poder y en la coexis- tencia de formas horizontales del ejercicio de ese poder.

La Figura $N^{\circ} 2$ muestra las estructuras de poder tradicional y moderna de la comunidad. Estas estructuras, sin embargo, no son necesariamente antagónicas sino que coexisten de forma tal que se puede dar el caso, como efectivamente ha ocurrido en el pasado, que el longko sea también el presidente. Asimismo, las autoridades unipersonales y colegiadas que operan en el plano tradicional también se yuxtaponen en el esquema moderno. La Figura $N^{\circ} 3$ ilustra esta complejidad, revelando la forma en que el poder fluye a través de las relaciones sociales y estructuras de poder formal e informal de la comunidad.

Figura $\mathrm{N}^{\circ} 2$

Comunidad de Quinquén. Estructura de poder tradicional (arriba) y moderna (abajo).

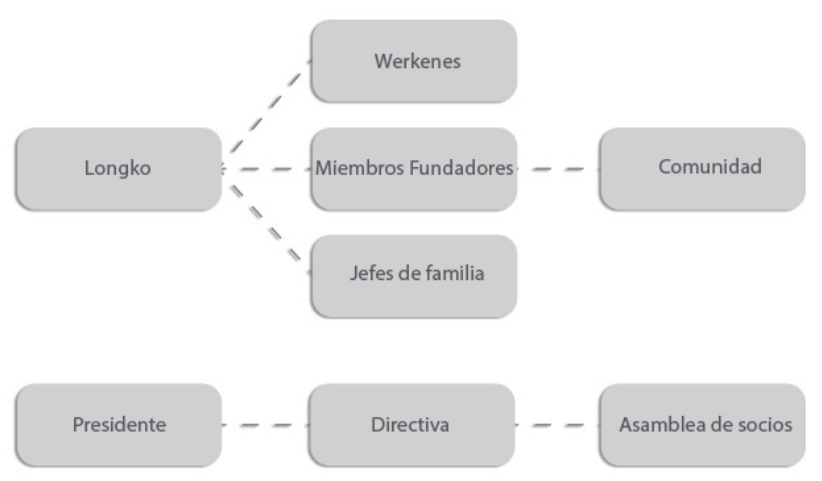

Fuente: Elaboración propia.

Figura $N^{\circ} 3$

Coexistencia de estructuras de autoridad y poder tradicionales y modernas

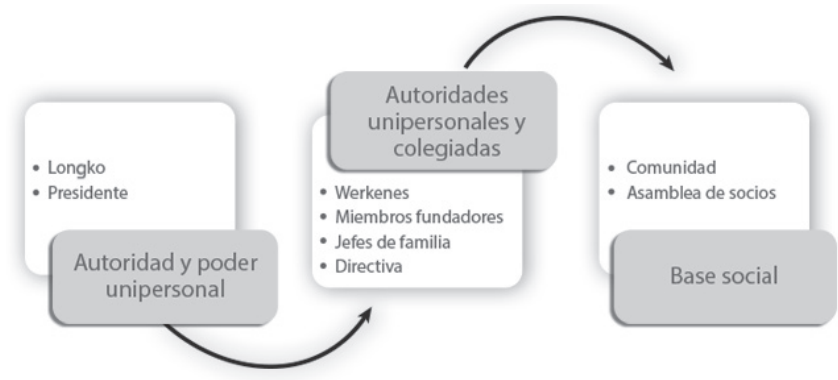

Fuente: Elaboración propia. 
A partir de la llamada emergencia indígena y la instalación programática de las políticas del reconocimiento, los marcadores étnicos cobran un nuevo significado y se hacen más visibles. En este nuevo contexto de "apreciación" hacia lo indígena la vestimenta tradicional ocupará un lugar prominente principalmente por dos razones: a) por su potencial revitalizador de la cultura, y b) por su eficacia en la restitución de la autoridad, legitimidad y prestigio hacia el mundo no indígena. Ambas razones están presentes en el uso estratégico que los habitantes de Quinquén hacen de su vestimenta.

Aparentemente, la vestimenta cotidiana pewenche en nada difiere a la de los campesinos y colonos que habitan la zona. Existen sin embargo algunos rasgos distintivos del vestuario que solo adquieren sentido en el universo mental indígena. En orden de jerarquía, destaca la manta de cacique que es la prenda usada por el longko cuando se requiere que sobresalga su investidura, por lo tanto esta prenda tiene un alto significado en los rituales del poder. Luego, está el ñimin-makuñ o poncho de trabajo, que es la prenda más característica de los pewenche al igual que sus polainas de cuero de chivo que cubren toda la pierna. El trarilonko, o cintillo de lana, solo es usado en ceremonias, en la actualidad estos cintillos llevan bordado el nombre del lof Quinquén. Casi sin excepción, los hombres usan alguna clase de sombrero, así mientras algunos adultos mayores usan un chumpiru, sombrero negro de paño, otros usan modernos gorros con visera, con todo no hay aquí una regla siendo el gorro o sombrero la parte del vestuario que exhibe la mayor heterogeneidad.

Las mujeres, en tanto, llevan indistintamente faldas o pantalones y en algunos casos un delantal de percala. La cabeza la cubren por un munulonco o pañuelo. En rituales y fiestas como el nguillatun y el we tripantu, se cubren la parte superior del cuerpo con un chamal o küpam que es una pieza de tela rectangular de color negro con una franja de color azul, rojo o verde; también se atan a la cintura un trariwe o faja. El atuendo es acompañado por joyas de gran formato destacando el trarilonko (cintillo de anillos), el trapelacuche o pectoral y un alfiler en forma de punta.
La vestimenta tradicional es un tema no exento de controversia, debido principalmente a la intervención del Estado. En efecto, muchos elementos del vestuario han sido adquiridos mediante proyectos en el marco del Programa Orígenes, en su componente "fortalecimiento de la identidad cultural"10. La intervención del Estado en la esfera de la cultura, es discutida por los críticos al multiculturalismo neoliberal por producir a los propios sujetos que gobierna (Boccara y Bolados, 2010), y por los críticos a los procesos de 'modernización/integración' por producir una clientela favorable al Estado (Bengoa y Caniguan, 2011: 23). Si bien estas críticas merecen consideración, no es menos cierto que por medio de este tipo de proyectos, muchas comunidades, como es el caso de Quinquén, han podido revitalizar algunas de sus prácticas ancestrales como la de la vestimenta ritual, cuya pérdida era también el resultado de la situación de pobreza en la que fueron históricamente sumidos. Asimismo, y como parece ser el caso, la recomposición de la vestimenta indígena tiene una alta eficacia performativa como herramienta de reivindicación política, como lo demuestra el uso político de las mantas de cacique y el de los trajes tradicionales en la mujeres (ver Figura $N^{\circ}$ 4). A este respecto, Bacigalupo (2010: 9) sostiene que si bien esta estética contribuye a la folclorización, también contribuye al desarrollo de sentimiento de resistencia mapuche.

\section{Formas de ejercer la autoridad}

La autoridad se manifiesta tácitamente en la mayoría de los casos, pero se hace más evidente en una noción compartida del significado de "respeto". Así, por ejemplo, todos los miembros de la comunidad reconocen en primer lugar el respeto debido al longko, lo mismo aplica al padre o jefe de familia o dueño de casa (hombre o mujer). En el pasado el respeto era una fuente de autoridad y

\footnotetext{
${ }^{10}$ Financiado parcialmente por el Banco Interamericano de Desarrollo, "Orígenes o Programa de DesarroIlo Integral de Comunidades Indígenas se empezó a implementar en Chile en el año 2001. Es un Programa de 133 millones de dólares que tiene como objetivo contribuir al desarrollo y mejoramiento de la calidad de vida de los pueblos aimara, atacameño y mapuche del sector rural" (Boccara y Bolados 2008: 169).
} 
Figura $\mathrm{N}^{\circ} 4$

Autoridades tradicionales pewenche vistiendo sus mantas de cacique. Marcha 12 agosto 2010 Lonquimay

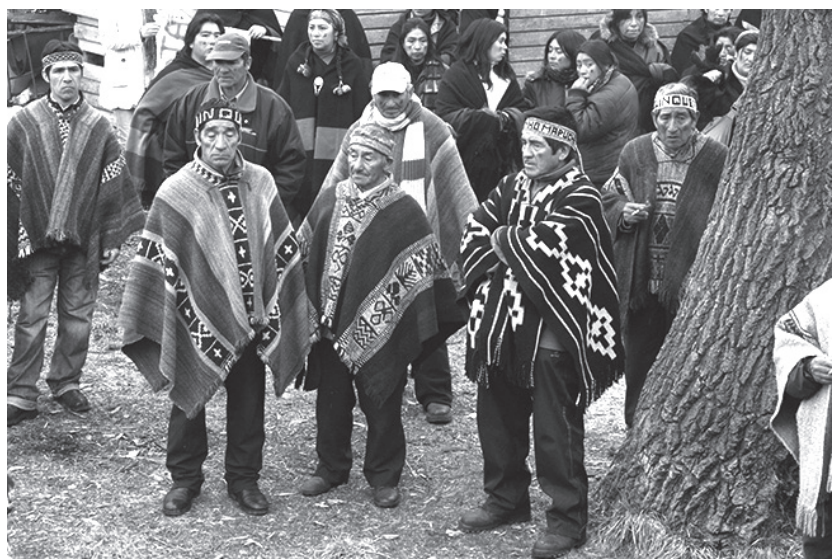

Fuente: Archivo personal del autor. Tomada con permiso.

en particular era una función de la capacidad que tenían los longkos para distribuir bienes o dones (Mauss, 2009). En la actualidad la autoridad del longko se ha debilitado precisamente porque ya no dispone de la capacidad donadora de antaño, la que ha sido reemplazada por las instituciones del Estado reconfigurando consecuentemente la relación mapuche-winka en lo referente a la autoridad y el don (Foerster y Menard, 2009).

También se respeta mucho a las ñañas ancianas, quienes desempeñan además un rol central en la crianza de los menores. El concepto de respeto es usado además para designar el ámbito de influencia de la autoridad, de modo tal que "hacerse respetar" es hacer valer un derecho sobre algo, esta expresión es usada frecuentemente para referirse al dominio que se tiene sobre el territorio y opera tanto colectiva como individualmente. Pero la autoridad también se ejerce de forma explícita como es el caso de las asambleas, donde quienes poseen más habilidades retóricas ejercen una mayor influencia sobre los demás, esto es particularmente importante considerando que la mayoría de los asuntos de dirimen por votación directa.

\section{Toma de decisiones}

Las decisiones comunitarias por lo general se toman en las asambleas y reuniones que son convocadas ad hoc, en estas reuniones se deciden asuntos que son de interés general como por ejemplo participar o no de determinado proyecto de desarrollo, participar como comunidad en alguna manifestación de carácter reivindicativo o hacer alguna solicitud formal a la autoridad política. Las reuniones cumplen además la función de servir como reguladoras del ejercicio del poder y son el espacio para confrontar posiciones encontradas, dado que todos los miembros están emparentados el tono de las discusiones es muy directo y suelen decirse las cosas cara a cara. Asimismo, si bien al menos potencialmente todos tienen voz, las reuniones por lo general son dominadas por los adultos quienes poseen mayor experiencia de negociación y por lo tanto mayor poder para ejercer influencia sobre el resto de la asamblea. Las mujeres en tanto rara vez participan de los procesos deliberativos.

\section{Estructura social}

La sociedad pewenche se estructura multiescalarmente en base a una serie de escalas o niveles que se relacionan entre sí mediante las prácticas sociales. En este esquema el che o "verdadera persona" (Course, 2011) ocupa el primer lugar, el che en su calidad de persona establece relaciones de distinto tipo con el resto de los miembros del grupo al que pertenece pero prevalecen las relaciones con su 
núcleo familiar directo. Una vez que se casa y forma una familia o caserado pasa a ser el ngen ruka, dueño de casa, luego al crecer sus hijos varones y casarse forman sus propio caserado y por regla general instalan su casa cerca de la de su padre, de esta forma las unidades domésticas se subdividen en función del número de hijos y van constituyendo una familia extendida bajo la autoridad del jefe de la familia que puede ser el abuelo o el padre.

Esta forma de distribución espacial de las unidades domésticas podría deberse a la persistencia de una práctica ancestral, como se infiere de la siguiente observación de Guevara (1908) "Así, un jefe de familia tiene sus habitaciones, dos o tres rucas, en que se albergan sus deudos inmediatos $\mathrm{i}$ allagados. A poca distancia vive una segunda familia con más o menos casas, en seguida otra i sucesivamente varias más, ligadas todas por vinculo de parentesco real o supuesto" (p.20). Esta familia extensa resultante, que puede llegar a cuatro generaciones, está en relación de proximidad y parentesco con las otras familias del grupo. Pese a esta proximidad, existen claras fronteras sociales que delimitan el espacio de autonomía de cada familia, aun cuando hay gran interacción entre ellas. Como consecuencia de estas interacciones se forma un entramado invisible o red de conexiones que se dan en un territorio geográficamente delimitado, esto es el lof o comunidad que a su vez forma parte de un conjunto más amplio de relaciones con otros lof, estos por su parte al estar también conectados entre sí forman la identidad territorial pewenche. La Figura $\mathrm{N}^{\circ} 5$ ilustra la forma en que se estructura una familia extendida, tomado de un ejemplo real en el que conviven cuatro generaciones.

Figura $\mathrm{N}^{\circ} 5$

Esquema idealizado de la estructuración familiar.

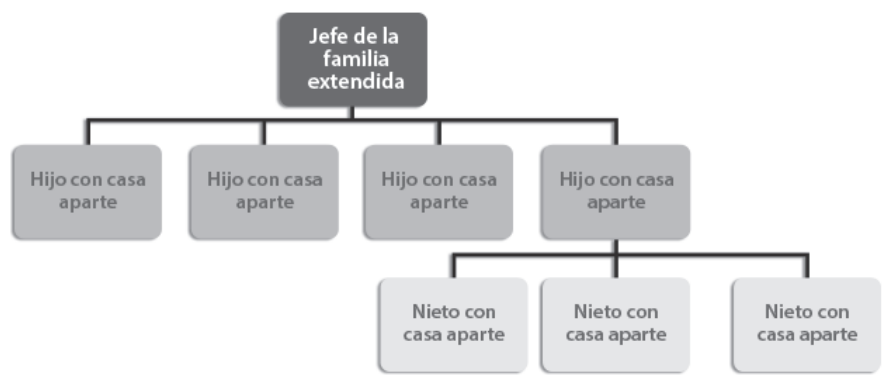

Fuente: Elaboración propia.

\section{Relaciones de parentesco}

La mayoría de los hombres de la comunidad están emparentados consanguíneamente y con alguna excepción todos provienen del mismo linaje fundado por don Mauricio Meliñir cuya presencia en el lugar se remonta a principios del siglo XX. Igualmente y como resultado de la mantención de las prácticas matrimoniales, casi todos los miembros mantienen lazos de afinidad que se expresan no solo en el orden genealógico sino también en la práctica cotidiana de llamarse mutuamente, de ahí que todos se llaman por el lazo de parentesco que los une, ocupando el primer lugar el de peñi (hermano) y luego el de tías, tíos, primas, primos, etc., a lo que se agrega el de padrinos. Un dato interesante es que la mayoría de los hombres se llaman entre sí "cumpitas" que se deriva de compadre, aun cuando no sean compadres en el sentido tradicional del concepto. Este dato, más que una simple anécdota, representa una práctica bien extendida entre los mapuche para reforzar los lazos de parentesco mediante la institución del compadrazgo sea este real o no. Stuchlik (1999) sostiene que el compadrazgo es una de las principales estrategias de reclu- 
tamiento social entre los mapuche y constituye por tanto una forma de reciprocidad, lo que se verifica en esta comunidad pewenche.

El lakutún es otra fórmula usada frecuentemente para fortalecer las relaciones de afinidad y por lo tanto, de gran significado para la cultura. Consiste en la capacidad para transferir en forma de donación el nombre propio de una persona, hombre o mujer, entre generaciones alternadas (Foerster, 2010). De esta manera, se refuerzan los lazos transgeneracionales y se mantiene la memoria del grupo. Este hecho, más que una simple forma de bautizar o dar nombre a las personas, implica el establecimiento de obligaciones mutuas con personas muertas o vivas; es en consecuencia una forma de relaciones sociales. Así dos personas se hacen laku en el acto de dar y recibir el mismo nombre, el que se transfiere de un mayor vivo a un menor con quien lo unirá un vínculo que no se termina con la muerte, esta práctica se conoce como lakutún. El siguiente ejemplo sirve para ilustrar la vigencia de este mecanismo de reproducción social: la señora Paulina Huaiquillán esposa del longko es laku de su tía Paulina Huaiquillán quien residía en la comunidad vecina de Pedregoso. Si bien la tía falleció, la institución del laku permite mantenerla viva en su sobrina contribuyendo con esto a fortalecer los lazos ancestrales y espirituales de la familia extendida.

\section{Prácticas matrimoniales}

Las prácticas matrimoniales constituyen uno de los rasgos más importantes en la producción de fronteras étnicas (Barth, 1969) entre los pewenche, aunque estas han sufrido importantes variaciones como pasar de la poligamia a la monogamia (Bengoa, 2000) ${ }^{11}$. En la actualidad las prácticas matrimoniales se vinculan al aseguramiento de derechos territoriales y a la mantención de las formas de autoridad, que se reflejan en la residencia patrilocal y la sucesión patrilineal. A fin de conservar la persistencia del linaje y la transmisión masculina de derechos, los hombres

\footnotetext{
11 Según Bengoa (2000: 156), para los mapuche del siglo XIX, los mayores focos de resistencia eran "que no nos vengan a imponer vivir en pueblos, y que no nos obliguen a la monogamia".
}

de la comunidad se casan con mujeres de otras comunidades, existiendo una preferencia por las mujeres de la Comunidad de Pedregoso que es la misma comunidad de donde proviene el linaje Meliñir. Esto se explica por tres razones: primero, por la proximidad geográfica con esa comunidad; segundo, por la mayor interacción entre las familias de ambas comunidades; $y$, tercero, por la existencia de una regla exogámica matrilateral según la cual los hombres se casan con la hija del hermano de la madre (Faron, 1969).

Antiguamente, los rituales matrimoniales incluían un estricto protocolo para la "petición de mano" de la novia junto con la negociación de una compensación material en especies, este proceso podía tomar varios días y requería el concurso de padrinos y representantes del novio. Una vez que se llegaba a acuerdo, se fijaba una fecha para la fiesta que se extendía por varios días. Esta costumbre de matrimonios a la "usanza antigua" se ha ido perdiendo y adaptándose a forma chilenas. Pese a ello, los matrimonios siguen manteniendo el carácter de alianzas territoriales y consecuentemente son fundamentales en la adquisición y reforzamiento de la condición de indígena.

\section{Organización familiar}

La unidad doméstica está organizada en torno a la autoridad del padre que hace las veces de jefe de familia; está compuesta por el matrimonio y los hijos solteros, hombres y mujeres que viven en la misma casa conformando un caserado. Un caserado también puede estar constituido por un solo individuo, hombre o mujer, en cualquier caso significa el tener "casa aparte". Una vez que los hijos se casan, tienen las siguientes opciones: si es hombre, trae a su mujer a vivir a la comunidad y forman una nueva familia; si es mujer, debe dejar la casa paterna y acompañar a su marido a su comunidad de origen por la regla de residencia patrilocal; en el caso de mujeres viudas, por lo general, vuelven a la casa de los padres. En su conjunto, el sistema de relaciones que se constituye al amparo de la familia extendida es el eje de la vida social.

Si bien las labores domésticas expresan cierta diferenciación de roles por género, 
no hay regla al respecto. Por ejemplo, los hombres efectúan labores como el arado de la tierra, la corta de leña, la movilización del ganado mayor y siembra. En el dominio público, las asambleas son consideradas casi dominio exclusivo de los hombres. La mujer, en tanto, se encarga de labores que incluyen la preparación de la comida, el cuidado de los niños menores en edad no escolar, la mantención del huerto, el cuidado de animales menores y aves, el hilado de lana y tejido a palillo o a telar. En la esfera pública, son el apoderado de los niños en la escuela y recientemente algunas se han integrado a las actividades de turismo comunitario. Pese a esta diferenciación por roles, existe un importante número de actividades que son ejecutadas por hombre y mujer juntos, entre estas se cuentan: cosecha y enfardado de pasto para el invierno, recolección de piñones, contabilidad y encierro de animales tales como cabras y ovejas y la compra mensual de víveres en el pueblo.

\section{Territorio}

La comunidad está localizada a una distancia aproximada de $35 \mathrm{~km}$ del límite con Argentina (medido desde la escuela al Paso Icalma) que no solo separa a los chilenos de los argentinos, sino que también divide al territorio pewenche que se extiende históricamente por ambos lados de esta frontera internacional. Este espacio está muy presente en el imaginario de la comunidad toda vez que el cerro Batea Mahuida, hito geográfico ubicado al sur de la comuna de Lonquimay por donde pasa el límite, es visible desde muchos lugares de Quinquén. Pero también esta localización fronteriza ha significado una configuración social en la que coexisten distintas subjetividades impuestas, tales como la de colonos nacionales y extranjeros y la de campesinos chilenos e indígenas, muchos de los cuales fueron repatriados desde la región argentina del Neuquén. En un trabajo reciente Canio y Pozo (2013: 324), documentan el relato de Nawelpi del año 1901 sobre la ocupación militar del territorio que tiene lugar en la laguna Gallatué. Este relato es consistente con las narrativas orales de la comunidad, que dan cuenta de la llegada de sus antepasados a este "lugar de refugio", que es el significado que dan a la voz Kmkeñ.
A nivel interno, los límites físicos son demarcados mediante diversos mecanismos. Por ejemplo, los límites territoriales de la comunidad que la separa de las comunidades vecinas están establecidos en función de los cordones montañosos presentes en toda la geografía y que actúan como barreras naturales. Estos forman cuencas y valles sobre los cuales está emplazada la comunidad. El río Ñireko que corre en dirección este y desemboca en la laguna Galletué actúa también como límite interno y externo. Pese a que estos límites están formalizados en escrituras públicas, aún persisten problemas de demarcación con la comunidad vecina de Pedregoso que se deben precisamente a una divergencia sobre el lugar donde debe estar la línea de separación.

Los límites internos, en tanto, son trazados principalmente en función de accidentes o hitos geográficos como divisorias de aguas, montañas, o quebradas a partir de los cuales se dibuja una línea imaginaria. El uso de líneas imaginarias como técnica de demarcación era una práctica común entre los agrimensores, geógrafos e ingenieros para la división predial ya a fines del siglo XIX, por lo cual sería inexacto atribuirla exclusivamente a los pewenche. Por el contrario, pareciera ser que la adopción de esta técnica por los indígenas es meramente de orden práctico y proviene precisamente del contacto permanente con esos profesionales, quienes veían en su uso una forma económica y rápida para establecer deslindes, toda vez que no era necesaria la construcción de cercos. Al constituirse la propiedad y subdividirse los predios en unidades de menor tamaño, la línea imaginaria progresivamente dejó de ser efectiva para dar lugar a áreas totalmente cerradas por estructuras físicas como alambradas y cierres perimetrales de empalizadas. En la actualidad y pese a existir un mayor número de herramientas y técnicas de demarcación, la línea imaginaria sigue siendo reconocida y respetada entre los miembros de la comunidad como la más eficaz forma de establecer límites.

La producción de límites sociales, en tanto, no es independiente de la producción de límites físicos y constituye una forma bien definida de fortalecer la territorialidad y el orden comunitario. Los límites sociales se expresan en la interacción multiescalar de la 
siguiente forma: a) entre los individuos con la comunidad, b) entre todos los miembros de la comunidad, y c) entre la comunidad con otras comunidades. Consecuentemente, los límites emergen de los campos de relaciones que vinculan lo individual con lo colectivo (Figura $\mathrm{N}^{\circ} 6$ ). Estos campos de relaciones se inician en el individuo, siguiendo con la unidad doméstica o caserado, de ahí se proyecta hacia la comunidad, hasta incluir a toda la identidad territorial pewenche, en su conjunto se trata de una verdadera topología de redes que configura la base del ordenamiento espacial.

Figura $\mathrm{N}^{\circ} 6$

Modelo simplificado de interacción multiescalar del lof-comunidad

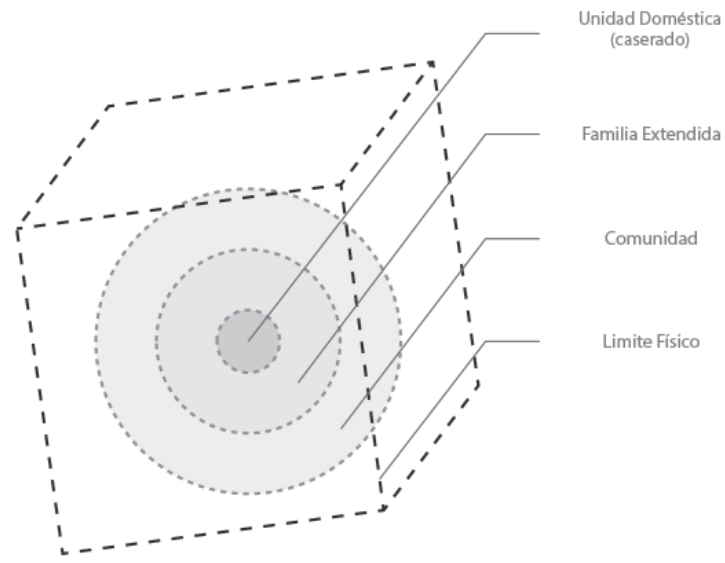

Fuente: Elaboración propia.

\section{Distribución del espacio territorial}

El espacio territorial comunitario se ha constituido en base a distintas lógicas, entre las que sobresale de manera incontrarrestable la intervención del Estado, en especial a partir del momento mismo en que el grupo se constituyó como comunidad indígena formal. No obstante, el peso del poder del Estado en la configuración del espacio territorial no ha significado -al menos totalmente- la desaparición de prácticas ancestrales en su ordenamiento, entre las que destaca la autoridad con la que cuenta el jefe de cada familia para distribuir derechos de goce entre sus hijos. Este derecho consiste principalmente en permitir al hijo que lo solicite -usualmente al momento de casarse- un espacio para la construcción de su casa en los límites del espacio asignado a la familia, de forma tal que el hijo aun cuando continúa bajo la tutela relativa del padre, obtiene cierta autonomía de este al formar su propia familia.
Este era básicamente el sistema antiguo para la subdivisión del espacio que en la práctica consagraba el derecho de propiedad. En la actualidad, y bajo la legislación indígena que rige desde 1993, este derecho puede ser solicitado también a la autoridad a fin de obtener un 'derecho real de uso' que permita a los tenedores postular a subsidios de vivienda.

Otra práctica que revela la persistencia de formas ancestrales de distribución de espacio es la autoridad de la comunidad para asignar espacios en el eltun cementerio, a fin de garantizar que todos al momento de morir puedan iniciar su viaje al wenupamu o tierra de arriba. Desde una perspectiva simbólica, una práctica de distribución de espacio la constituye la autorización que da la comunidad por intermedio del longko para la instalación de un küni o ramada en la ceremonia del nguillatún, lo cual otorga el derecho a participar de dicha ceremonia como una unidad familiar independiente, en un espacio distinto al del 
padre. Este no es un derecho adquirido por el mero hecho de pertenecer a la comunidad sino que es el resultado de un proceso de negociación que involucra elementos de autonomía, autoridad y prestigio.

\section{Uso del territorio}

El ciclo invernada-veranada corresponde a una dinámica tradicional de uso del espacio territorial que permite explicar la persistencia y reproducción de la cultura pewenche de Quinquén. En efecto, esta dinámica da cuenta de la forma en que las familias y los individuos se relacionan con el territorio a fin de hacer uso de los recursos naturales para asegurar la existencia material y la forma de vida. El ciclo invernada-veranada no debería ser visto meramente desde una lógica binaria abajo-arriba o como una modalidad de control vertical de pisos ecológicos, ni como una forma de trashumancia. Por el contrario debería examinarse desde múltiples dimensiones, teniendo en cuenta que se trata de una forma de articulación que designa varias cosas por separado y todas a la vez. Así, por ejemplo, se usa para designar espacios, prácticas sociales y modos de producción. En consecuencia, mientras que es cada una de esas cosas, un enfoque más productivo sería verlas de forma relacional.

- Como espacios: La invernada es un espacio perfectamente delimitado, donde las familias tienen sus animales, cocina de fogón (Figura $N^{\circ} 7 \mathrm{~A}$ ), corrales, galpón, huerto, leñera, sembradíos y demás elementos esenciales para la vida. Allí las familias permanecen de manera estable la mayor parte del tiempo realizando distintos tipos de actividad dependiendo de la disponibilidad de recursos y de la época del año; se trata entonces del lugar donde tienen la casa. La veranada, en tanto, es un espacio delimitado de manera más amplia hacia donde las familias se movilizan durante la época estival a fin de obtener los recursos que complementan su sistema económico entre los que se destacan: el pasto para los animales, los piñones y la leña. Estos espacios están asignados a cada familia, aunque también existen algunos de uso común. Durante el tiempo que dura el "veraneo", permanecen en lo que se conoce como un puesto de ve- ranada que es una unidad que consta de corral y una estructura de canoga (madera rústica con techo de zinc), donde acopian los piñones y duermen (Figura $\mathrm{N}^{\circ} 7 \mathrm{~B}$ y $N^{\circ} 7 \mathrm{C}$ ). En la actualidad, también algunas estructuras se han reconstruidos con fines turísticos (Figura $N^{\circ} 7 \mathrm{D}$ ). Originalmente, todo el sector donde hoy se emplaza la comunidad era usado como "sitio de veranada"; de hecho, fue precisamente debido a la repetición ininterrumpida del ciclo que la familia Meliñir fue adquiriendo derechos sobre el espacio ancestral.

- Como práctica: El ciclo invernada-veranada constituye también un práctica social que da significado al modo de ser pewenche $y$ es en alguna medida uno de sus rasgos más distintivos, aunque el menos visible a los ojos externos. En efecto, mientras que algunos ven en este patrón de uso del espacio un resabio de prácticas poco eficientes, lo cierto es que han demostrado ser altamente efectivas en la reproducción del sistema de económico y cultural de esta comunidad. Asimismo, el hecho de que en la mayoría de los casos el sitio de invernada y veranada sean contiguos, hace difícil establecer cuándo comienza y cuándo termina un ciclo. De hecho, es común que en el mismo día, especialmente durante el verano, algunas familias realicen una jornada de recolección en su puesto de veranada, pero vuelvan a su casa a dormir. En estricto rigor se trata de una actividad permanente sin principio ni final, por lo tanto cualquier intento de separación resultaría improductivo ${ }^{12}$.

12 Esta observación, no debería considerarse como una regla general que define el ciclo invernada-veranada, como una práctica social que se ejecuta igual y de la misma forma entre todos los pewenche. Se trata entonces de una información proveniente del contexto específico de la realidad de Quinquén. Tuve la oportunidad de visitar las veranadas de Pehuenco, Pulul y el Tiriento en Lonquimay, donde las familias se instalan con todos sus enseres desde el inicio del verano hasta el fin de la temporada de piñoneo, lo que coincide con el inicio del otoño. También visité la veranada Koñiñamco en el sector de Pitril en el Alto Biobío, donde el ciclo tiene un carácter trashumante. En consecuencia, existe una amplia variabilidad en la forma en que se ejerce este control espacial el que en gran medida está determinado por la continuidad territorial entre el lugar de residencia y los lugares de pastoreo y recolección (Huiliñir, 2010). 
- Como modo de producción: El ciclo invernada-veranada representa más claramente que cualquier otro rasgo identitario el modo de producción pewenche. Efectivamente, es mediante este sistema de uso del espacio que las familias despliegan sus estrategias de vida, basadas principalmente en mecanismos de complementariedad ecológica. Si bien son mecanismos relativamente simples en su ejecución, no deberían ser vistos desde una perspectiva simplista, es decir el ciclo invernadaveranada va mucho más allá que el control vertical de recursos, la movilidad de animales o la recolección de piñones. Se trata más bien de un complejo sistema de interacción hombre-naturaleza, que constituye la base de la economía moral del grupo (Scott, 1977), proporcionando a todos sus miembros los recursos básicos para su supervivencia.

Figura $\mathrm{N}^{\circ} 7$

Estructuras tradicionales pewenche. (A) Cocina de fogón en invernada, sector el Cajón. (B) Puesto de veranada, sector Rankewe. (C) Puesto de piñoneo compartido, sector El Trillento. (D) Cocina de fogón para actividades de turismo.

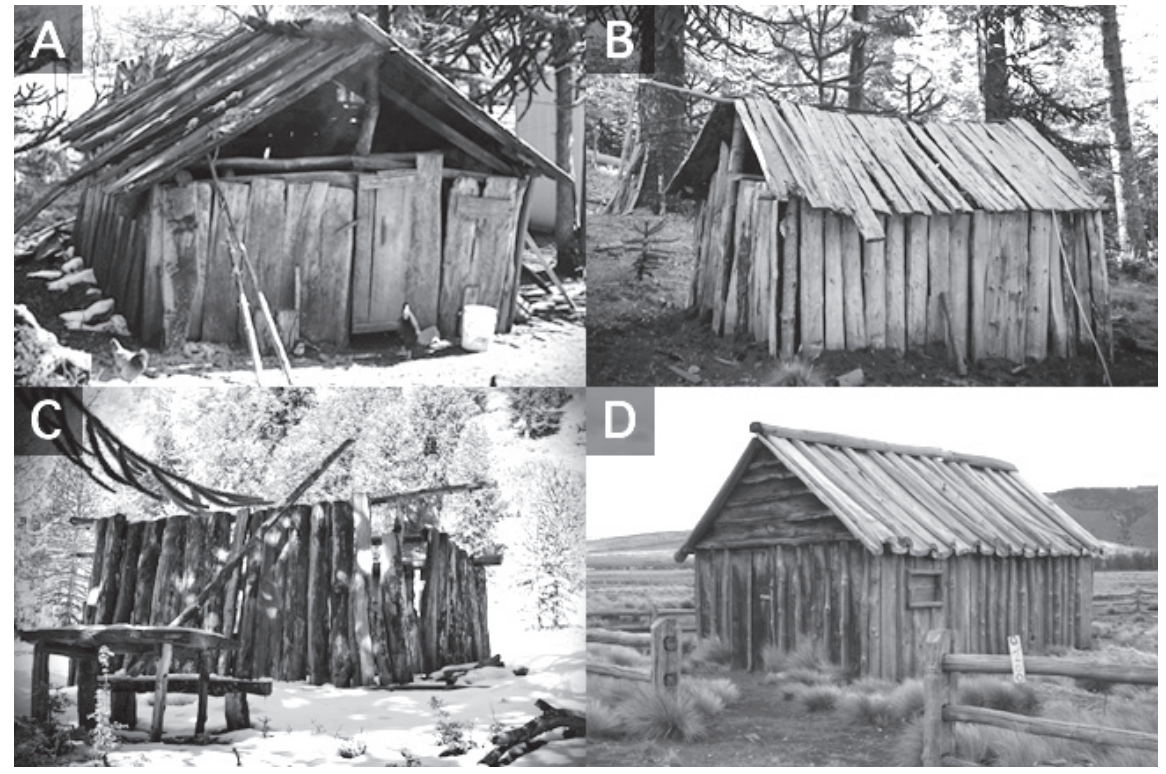

Fuente: Archivo personal del autor. Tomadas con permiso.

\section{Espacios de significación cultural}

En la geografía pewenche, virtualmente, todos los espacios tienen un significado cultural. Es posible, sin embargo, establecer entre ellos algunas diferencias de orden jerárquico. En el caso específico de Quinquén, esto se confirma en la identificación de sitios de importancia ceremonial, ecológica y económica, con los cuales los habitantes establecen relaciones de interdependencia.

Entre los sitios de significación ceremonial destaca en primer lugar el ngillatuwe, área destinada a la celebración del ritual del nguillatún o rogativa. En este espacio semicircular de aproximadamente 45 metros de diámetro, con su abertura orientada hacia el puel mapu (este), se reconstruye cada año un complejo ceremonial, al centro del cual se ubica el rewe o altar, que en el caso pewenche es una araucaria joven que se corta exclusivamente para servir este propósito. En el contorno de este semicírculo, se construyen estructuras de madera o ramadas cubiertas de ramas de coihue donde se ubican los cacerados que participarán en el ritual. El ngillatuwe representa para los miembros de la comuni- 
dad el lugar más sagrado, pues es aquí donde cada año se invoca al Chao Ngenechen o gran creador, tanto para agradecer los dones recibidos, como para pedir abundancia de ellos, lo que incluye animales, cosechas y piñones.

El eltuwe (cementerio) es otro sitio de uso ceremonial, destinado a la celebración del eluwün o ritual de enterramiento. Aquí se encuentran los restos de los antepasados y parientes directos de las familias que viven en la comunidad, pues solo ellos pueden descansar ahí. El eltuwe es considerado también un lugar sagrado, pues es desde allí donde los difuntos inician su viaje hacia el wenu mapu o tierra de arriba donde están quienes "vivieron en la tierra y subieron arriba" (Grebe et al., 1972: 66).

Los sitios de importancia ecológica corresponden a áreas naturales que pueden dividirse entre pinalerías, montañas y acuíferos. Las pinalerías son probablemente los espacios de mayor importancia en la organización de la vida pewenche, debido a la fuerte conexión con el pewen (araucaria araucana). Literalmente, los pewenche son la gente -che- del pewen -araucaria-. Curiosamente, sin embargo, ellos raramente se refieren al árbol en su lengua y lo llaman en cambio como pino araucaria; de ahí entonces que una concentración de estos árboles sea conocida como pinalería. Estos lugares tienen un dueño o espíritu protector, Ngen-Pewen, que es el dueño del bosque de araucarias (Grebe, 2006: 63). Su mayor importancia es ser el lugar donde se recolecta el ngülliw o piñón, que es la semilla del árbol que además constituye la base de la alimentación familiar. A esta práctica específica de recolección se le conoce como piñoneo. En el pasado estos lugares eran también un refugio al que acudían cada verano las familias pewenche que habitaban las laderas occidentales de la cordillera de los Andes, con el fin de cazar, recolectar piñones y secar carne. Si bien, eran espacios a los que se tenía libre acceso, existían acuerdos sobre qué área le correspondía a cada linaje. Con la formación de las reducciones indígenas y la entrega de títulos de merced, hacia fines del siglo XIX, estos espacios, bien diferenciados, que coincidían además con los lugares de veranada, quedaron fuera de los títulos, en los que se incluyó solamente el lugar donde estaban las viviendas principales, en las invernadas. El resto de los espacios fueron rematados a particulares. En consecuencia, las nuevas reducciones se encontraron con el hecho de tener que solicitar permiso a actores no pewenche, incluido el Estado, para poder acceder a las pinalerías dando lugar a un sistema que consagraba, por una parte, derechos de propiedad y, por la otra, derechos de acceso. En la actualidad y en virtud del crecimiento de la población de Quinquén, cada familia dispone de un sitio bien delimitado para el piñoneo, por lo general contiguo a la invernada.

La mawida (montaña) es un área que posee un carácter distintivo en el imaginario cultural pewenche. Objetivamente, su presencia es notoria en todo el paisaje de la comunidad, pero los significados que esconde así como su carácter sagrado solo se comprenden desde el universo pewenche. Una indicación bien característica de aquello es la observancia de un pequeño ritual que se ejecuta como muestra de respeto al ingresar a ese espacio. Los pewenche creen que todos los lugares poseen un dueño o ngen (Grebe, 1993); en el caso de la montaña es el ngen mawida, quien es además el protector de todos los seres del mundo natural y sobrenatural que allí habitan. Entre los primeros destaca el pangue o trapial, león o puma, con el cual los pewenche establecen una relación muy estrecha al punto de ser conocido como el ta peñi (hermano mayor). Si bien no hay testimonios de ataques a personas, los ataques al ganado menor son relativamente frecuentes, en especial en primavera. En la montaña también habita el ngürü o zorro, cuya figura es omnipresente, en primer lugar porque es el ser que da el nombre al linaje y en segundo lugar por los ataques furtivos a las aves de corral. Al igual que ocurre con el tapeñi al ngürü no se le captura ni da muerte, por último el ngürü se manifiesta en la narrativa oral que se expresa en los epew o cuentos, conocidos por todos los miembros de la comunidad, aunque solo los epewtufe contadores de cuentos poseen el don para contarlos. Guevara (1911) apunta que "en sus refranes zoológicos desempeña el zorro un papel principal, tanto por ser personificación de la astucia i, por consiguiente, el héroe de sus cuentos, cuanto por convertirse con frecuencia en animal nocivo i misterioso que 
ronda en la noche como agente de una vieja bruja (p.10).

En la montaña también habitan aves como el manke o cóndor que, de gran tamaño, sobrevuela los cielos de la comunidad. La presencia del cóndor es muy evidente y es frecuente verlo planear a gran altura en días claros; esta presencia además se manifiesta en el nombre de la cumbre más alta del territorio, el cerro Manquewe o Ranquewe (no existe acuerdo en la forma de designarlo lo cierto es que el nombre deriva de la presencia de nidos de cóndores). Otra ave que goza de gran significación es el ñancu o águila, cuya presencia es también visible en los cielos. La importancia de esta ave es que está en el apellido materno de los hijos nacido de la unión de una pareja de miembros fundadores de la comunidad. Otra ave bien característica que habita la montaña es el rere, pájaro carpintero, que no siempre se puede ver pero casi siempre se puede oír. Por último y aunque más raro de ver, la montaña es el hábitat del nuku o búho, asociado a presagios negativos (Villagrán et al., 1999).

El territorio comunitario es cruzado por una serie de cursos de agua de carácter permanente, entre estos destacan el río Quinquén que al confluir con el Zanueco da nacimiento al Ñireco. Estos ríos con sus afluentes y quebradas sirven como límites naturales y son además la principal fuente de abastecimiento de agua para los ecosistemas de pradera. Estas aguas superficiales desembocan en la laguna Galletué que conjuntamente con la laguna de Icalma dan origen a una de las mayores cuencas hidrográficas del país, cuyo cauce principal es el río Biobío. Este río es el de mayor importancia geográfica e histórica en las relaciones entre el pueblo mapuche y el resto de la sociedad chilena ${ }^{13}$.

\footnotetext{
13 Desde una perspectiva geohistórica (Molina, 2012), el río Biobío constituye la línea divisoria entre la nación chilena y la nación mapuche (Téllez et al., 2011). En efecto, desde la colonia el río fue reconocido como la frontera norte que delimitaba el espacio jurisdiccional conocido como territorio indígena y sobre el cual los mapuche tenían soberanía, la que se extendía por el sur hasta el río Toltén. Esa área intermedia corresponde a lo que comúnmente se conoce la Araucanía tradicional (Urbina, 2009), también designada como "La Frontera".
}

Finalmente, los mallines constituyen espacios con características bien definidas, corresponden a formaciones vegetacionales herbáceas con abundante humedad que se encuentran localizados en los valles y en altura, aunque no homogéneamente distribuidos. Dadas las condiciones climáticas, la presencia de suelos volcánicos y la irregular topografía del lugar, los mallines son espacios de gran valor económico puesto que son reservas naturales de pasto, hasta allí entonces son movilizados los animales a la entrada del verano. Su formación es permitida por la presencia de menukos que corresponden a afloramientos de agua de alta significación cultural. Estos lugares también poseen un ngen o dueño que es invocado para que se mantenga flujo permanente de agua. En estos acuíferos también habita el punalka que es un espíritu maligno. Los saltos o saltillos son también lugares que gozan de un especial significado en la cosmovisión pewenche, ya que poseerían una alta concentración de newen, energía que se transfiere a los hombres y les da fortaleza. Precisamente, una de las prácticas no ritualizadas más poderosas es el dar y recibir newen, consistiendo más bien en un acto performativo del habla, es decir el acto se produce en el momento mismo de la enunciación de la palabra (Course, 2012).

\section{El retorno de los ancestros: reflexiones finales sobre la importancia de las geografías indígenas}

En el marco de la llamada emergencia étnica y en la coyuntura de los 500 años de la invasión europea al continente, la comunidad pewenche de Quinquén alcanzó notoriedad por su lucha para lograr el reconocimiento al derecho de primeros ocupantes sobre las tierras que actualmente habita. El reconocimiento de estos derechos finalmente se obtuvo y la comunidad recibió sus títulos de propiedad el año 2007. A partir de entonces, e incluso antes, los habitantes de la comunidad han comenzado un interesante proceso de reestructuración profunda de sus prácticas más tradicionales y que configuran lo que aquí se ha llamado un proceso continuo de ancestralización del territorio. 
Este proceso de ancestralización subyace a varios aspectos de la vida en Quinquén, haciéndose sobresaliente e incluso visible de múltiples formas, tanto hacia el interior como hacia el exterior de la comunidad. Como parte de esta dinámica la invocación a lo ancestral puede tener un carácter estratégico, toda vez que es empleada por una parte, para legitimar la autoridad de longko en la propia comunidad y por la otra, para exhibir hacia el exterior la fortaleza espiritual o newen que le otorgaría contar una machi, ambas figuras encarnan la máxima expresión del poder ancestral de todo el pueblo mapuche. Así, dos instituciones consideradas en declive, pueden ser revitalizadas mediante antiguas y nuevas formas de relacionarse con el poder; el del mundo terrenal y el de los espíritus.

La ancestralización también está contenida en la forma multiescalar en que se organiza el entorno social, comenzando a nivel de la identidad individual conectada a la estructura familiar mediante las relaciones de parentesco consanguíneo y por afinidad, que se expresan en la mantención de alianzas matrimoniales preferentes con una comunidad vecina, vinculándose de esta forma en agregados mayores que conforman la identidad territorial pewenche. Pero las interacciones con el territorio revelan también la existencia de protocolos para acceder, controlar y usar los recursos que aseguren la subsistencia. Anclado a estos protocolos se observa la coexistencia de seres del mundo natural y sobrenatural entre los que se establecen relaciones de mutua dependencia, estas interacciones han mostrado una fuerte persistencia en el tiempo, como el ciclo invernada-veranda y una marcada continuidad en el espacio expresada en el establecimiento de deslindes, fronteras y límites cuyos trazados no han borrado completamente las formas de significar el espacio a la usanza ancestral.

Sin pretender definiciones absolutas o totalizantes, este artículo ha presentado evidencia para ayudar a comprender mejor el significado de la dimensión ancestral de la vida en la comunidad pewenche de Quinquén. Con ello, se ha buscado avanzar hacia una mayor complejización en el análisis de las dinámicas territoriales, que trascienda enfoques a veces estáticos de lo ancestral y que tienden a relegarlo a un tiempo inmemorial o a ubicarlo en discursos primordialistas. La integración analítica de las prácticas cotidianas de la comunidad vinculadas al contexto externo, ha permitido revelar la existencia de una geografía indígena sustentada en el conocimiento, la experiencia y la vivencia del territorio. Una mayor consideración a estos aspectos, podría contribuir a una necesaria reflexión sobre lo que es vivir en una comunidad indígena. Pero más importante aún, podría contribuir a entender lo que significa hoy en día ser pewenche.

\section{Referencias bibliográficas}

ARAVENA PAILLALEF, G. Sistemas pecuarios en comunidades Mapuche. Temuco: Instituto de Estudios Indígenas, Universidad de La Frontera, 1995.

AYLWIN, J. y CUADRA, X. Los desafíos de la conservación en los territorios indígenas en Chile. Temuco: Observatorio de Derechos de los Pueblos Indígenas, 2011.

COMISIÓN DE TRABAJO AUTÓNOMO MAPUCHE (COTAM). Informe de la Comisión verdad histórica y nuevo trato, Volumen III, Tomo 2: Primera parte del informe final de la Comisión de Trabajo Autónomo Mapuche. Mapu Küpal Azkunun Zugu. Fundamentos y Manifestaciones del derecho propio mapuche, 2003.

BACIGALUPO, A. La voz del kultrun en la modernidad: Tradición y cambio en la terapéutica de siete Machi Mapuche. Santiago de Chile: Ediciones Universidad Católica de Chile, 2001.

BACIGALUPO, A. Las prácticas espirituales de poder de los machi y su relación con la resistencia mapuche y el Estado chileno. Revista Chilena de Antropología, 2010, Vol. 7, No 21.

BARTH, F. Los grupos étnicos y sus fronteras. La organización social de las diferencias culturales. Introducción. México: Fondo de Cultura Económica, 1969.

BENGOA, J. Quinquén: cien años de historia pehuenche. Santiago de Chile: Ediciones Chile América CESOC, 1992. 
BENGOA, J. Historia del pueblo mapuche: siglo XIX y XX. Santiago de Chile: Ed. Sur, 2000.

BENGOA, J. y CANIGUAN, N. Chile: los mapuches y el Bicentenario. Cuadernos de antropología social, 2011, N³4, p. 7-28.

BOCCARA, G. Etnogubernamentalidad: la formación del campo de la salud intercultural en Chile. Chungará, 2007, Vol. 39, № 2, p. 185-207.

BOCCARA, G. y BOLADOS, P. ¿Dominar a través de la participación?: El neoindigenismo en el Chile de la posdictadura. Memoria americana, 2008, No 16-2, p. 167-196.

BOCCARA, G. y BOLADOS, P. ¿Qué es el multiculturalismo? La nueva cuestión étnica en el Chile neoliberal. Revista de Indias, 2010, Vol. 70, No 250, p. 651-690.

BRYAN, J. y WOOD, D. Weaponizing Maps: Indigenous Peoples and Counterinsurgency in the Americas. New York: Guilford Publications, 2015.

CANIO, M. y POZO, G. Historia y conocimiento oral mapuche: sobrevivientes de la "Campaña del Desierto y "Ocupación de la Araucania" (1899-1926). Santiago de Chile: LOM Ediciones. 2013.

COURSE, M. Becoming Mapuche: Person and ritual in indigenous Chile. Champaign: University of Illinois Press, 2011.

COURSE, M. The birth of the word: Language, force, and Mapuche ritual authority. HAU: Journal of Ethnographic Theory, 2012, Vol. 2, $\mathrm{N}^{\circ} 1$, p. 1-26.

DILLEHAY, T. La influencia política de los (las) chamanes mapuches. Cultura-HombreSociedad CUHSO, 1985, Vol. 2, $\mathrm{N}^{\circ} 2$, p. 141-157.

FARON, L. Los mapuches. Su estructura Social. México: Instituto Indigenista Americano, 1969

FOERSTER, R. Introducción a la religiosidad mapuche. Santiago de Chile: Editorial Universitaria, 1993.
FOERSTER, R. y MENARD, A. Futatrokikelu: Don y autoridad en la relación mapuchewingka. Atenea, 2009, N 499, p. 33-59.

FOERSTER, R. Acerca de los nombres de las personas (üy) entre los mapuches. Otra vuelta de tuerca. Revista de Antropología, 2010, No 21, p. 81-109.

GORDON, E. \& HALE, Ch. Rights, Resources, and the Social Memory of Struggle: Reflections and Black Community Land Rights on Nicaragua's Atlantic Coast. Human organization, 2003, Vol. 62, N 4, p. 369-381.

GREBE, M.; PACHECO, S. y SEGURA, J. Cosmovisión mapuche. Cuadernos de la realidad nacional, 1972, Vol. 14, p. 46-73.

GREBE, M. El Kultrún Mapuche: Un Microcosmo Simbólico. Revista Musical Chilena, 1973, Vol. 27, No 123-124, p. 3-42.

GREBE, M. El subsistema de los ngen en la religiosidad mapuche. Revista Chilena de Antropología, 1993-1994, N²12, p. 45-64.

GREBE, M. Culturas Indígenas de Chile: Un estudio preliminar. Santiago de Chile: Pehuén, 2006.

GUEVARA, T. Historia de la civilización de Araucanía: Psicolojía del pueblo araucano. Santiago de Chile: Imprenta Cervantes, 1908.

GUEVARA, T. Folklore araucano. Santiago de Chile: Imprenta Cervantes, 1911.

GUYOT, S. \& SEPÚlVEDA, B. The New Borders of Participation in Protected Areas, from Ethnicisation to Local (Dis) Integration: The Case of Chile. In: RAMUTSINDELA, M. Cartographies of nature: how nature conservation animates borders. Newcastle upon Tyne: Cambridge Scholars Publ, 2014, p. 193-217.

HIRT, I. Descolonizando y reconstruyendo el lof: Procesos de autonomía mapuche en el Sur de Chile, a través de una experiencia de cartografía indígena. En: GONZÁLEZ, P.; BARAHONA, M.; GARRIDO, M. y JOO, J. Resistencia territorial en América Latina. Los espacios como posibilidad y como potencia. 
Santiago de Chile: Universidad Academia de Humanismo Cristiano, 2006, p. 43-77.

HIRT, I. Mapping Dreams/Dreaming Maps: Bridging Indigenous and Western Geographical Knowledge. Cartographica: The International Journal for Geographic Information and Geovisualization, 2012, № , 47, p. 105-120.

HUILIÑIR, V. El Rol de las Veranadas en el Territorio Pewenche de Alto Biobío. Sector Lonquimay, IX Región. Revista Geográfica Despertando Latitudes, 2010, N² 2, p. 17-24.

LATCHAM, R. La organización social y las creencias religiosas de los antiguos araucanos. Santiago de Chile: Museo de Etnología y Antropología de Chile, 1924.

LENZ, R. Estudios araucanos; materiales para el estudio de la lengua, la literatura i las costumbres de los indios mapuche o araucanos. Santiago de Chile: Imprenta Cervantes, 1897.

MAUSS, M. Ensayo sobre el don. Buenos Aires: Katz editores, 2009.

MOLINA, R. Reconstrucción de los etnoterritorios. En: AYLWIN, J.; CARRASCO, H. y MARTÍNEZ, C. (editores). Tierra, Territorio y Derecho Indígena. Temuco: IEI-UFRO, 1995, p. 111-118.

MOLINA, R. Geografías mapuches: territorios, política y desafíos en tiempos de cambio. Revista Geográfica del Sur, 2012, Vol. 3, $\mathrm{N}^{\circ} 1$, p.15-36.

NEIRA CEBALLOS, Z.; ALARCÓN, A.; JELVES, I.; OVALLE, P.; CONEJEROS, A.M. \& VERDUGO, V. Espacios ecológico-culturales en un territorio mapuche de la región de la Araucanía en Chile. Chungará. Revista de Antropología Chilena, 2012, Vol. 44, N², p. 313-323.

NIETSCHMANN, B. The unknown war: The Miskito nation, Nicaragua, and the United States. New York: Freedom House \& University, 1989.
NIETSCHMANN, B. Conservation by conflict in Nicaragua. Natural History, 1990, Vol. 99, $\mathrm{N}^{\circ} 11$, p. 42-49.

NIETSCHMANN, B. Conservación, autodeterminación y el área protegida Costa Miskita, Nicaragua. Mesoamerica, 1995, $\mathrm{N}^{\circ}$ 29 , p. $1-55$.

OFFEN, K. Narrating Place and Identity, or Mapping Miskitu Land Claims in Northeastern Nicaragua. Human Organization, 2003, $\mathrm{N}^{\circ}$ 62, p. 382-392.

OFFEN, K. El mapeo de la mosquitia colonial y las prácticas espaciales de los pueblos mosquitos. Mesoamérica, 2008, N 50, p. $1-36$.

OFFEN, K. O mapeas o te mapean: Mapeo indígena y negro en América Latina. Tabula Rasa, 2009, №10, p. 163-189.

PALOMINO-SCHALSCHA, M. Descolonización, fronteras y lugar: desafiando la exclusión a través de la relacionalidad en la experiencia de Trekaleyin, Alto Bío Bío. Revista Geográfica del Sur, 2012, Vol. 3, N 1, p. 91-112.

PHILO, C. More words, more worlds: reflections on the 'cultural turn'and human geography. In: COOK, I.G.; CROUCH, D. \& NAYLOR, S. Cultural turns/geographical turns perspectives on cultural geography. Harlow: Prentice Hall, 2000, p. 26-53.

RESTREPO, E. Teorías contemporáneas de la etnicidad: Stuart Hall y Michel Foucault. Popayán: Editorial Universidad del Cauca, 2004.

SEPÚLVEDA, B. El territorio mapuche en Chile: perspectivas geográficas. Revista Geográfica del Sur, 2012, Vol. 3, № 1, p. 9-13.

SCOTT, J.C. The moral economy of the peasant: Rebellion and subsistence in Southeast Asia. New Haven: Yale University Press, 1977

TÉLLEZ, E.; SILVA, O.; CARRIER, A. y ROJAS, V. El tratado de Tapihue entre ciertos linajes mapuches y el gobierno de Chile 
(1825). Cuadernos de Historia, 2011, N³5, p. 169-190.

STUCHLIK, M. La vida en mediería. Santiago de Chile: Soles Ediciones, 1999.

URBINA CARRASCO, M. La frontera de arriba en Chile colonial. Interacción hispanoindígena en el territorio entre Valdivia y Chiloé e imaginario de sus bordes geográficos, 1600-1800. Valparaíso/Santiago de Chile: Ediciones Universitarias de Valparaíso/Centro de Investigaciones Diego Barros Arana, 2009.

CAROLINA VILLAGRÁN, C.; VILLA, R.; HINOJOSA, L.P.; SÁNCHEZ, G.; ROMO, M.; MALDONADO, A.; CAVIERES, L.; LATORRE, C.; CUEVAS, J.; CASTRO, S.; PAPIC, C. y VALENZUELA, A. Etnozoología Mapuche: un estudio preliminar. Revista Chilena de Historia Natural, 1999, Vol. 72, p. 595-627.
WAINWRIGHT, J. \& BRYAN, J. Cartography, territory, property: postcolonial reflections on indigenous counter-mapping in Nicaragua and Belize. Cultural Geographies, 2009, Vol. 16, № 2, p. 153-178.

WAINWRIGHT, J. Decolonizing development: colonial power and the Maya. New York: John Wiley \& Sons, 2011.

ZAVALA, J.M. Los mapuches del siglo XVIII. Dinámica interétnica y estrategias de resistencia. Santiago de Chile: Universidad Bolivariana, 2008. 
